\title{
Common infectious agents in multiple sclerosis: a case-control study in children
}

\author{
Bernd Krone ${ }^{1}$, Daniela Pohl ${ }^{2 *}$, Kevin Rostasy ${ }^{2,3 *}$, Elke Kahler ${ }^{4}$, Edgar Brunner 4 , \\ Frank Oeffner ${ }^{1,5 *}$, John M Grange ${ }^{6}$, Jutta Gärtner ${ }^{2}$ and Folker Hanefeld ${ }^{2}$
}

\begin{abstract}
Environmental factors, in particular infections, have been linked with the risk of developing multiple sclerosis (MS). The association of Epstein-Barr virus infection with childhood onset of MS has been recently recognized. As other infections characteristically experienced during childhood have not yet been studied in larger cohorts of paediatric MS, we conducted a study on 152 German children with MS (age at onset $<16$ years) and matched controls in the hope of gaining evidence for their possible aetiological role in MS. Patterns of antibody responses were determined to a range of infections which, in prior studies principally on adult patients, had revealed possible associations with MS. In this study on children the serology of several infections showed associations with MS. In the exceptional case of Chlamydia pneumoniae there was a significantly higher prevalence of IgM antibody but, more typically, as in the case of influenza A, measles, parainfluenza 2, varicella/zoster viruses and particularly to the herpes simplex virus type 2 (HSV-2) lysate antigen, there were significantly higher concentrations of IgG antibody. Additional investigations, however, make it highly unlikely that a relevant number of children have experienced infections with HSV-2. In general this study supports and emphasizes a complex infectious and immunologic background of MS. Multiple Sclerosis 2008; 14: 136-139. http://msj.sagepub.com
\end{abstract}

Key words: childhood infections; Epstein-Barr virus; paediatric multiple sclerosis

\section{Introduction}

The epidemiological features of multiple sclerosis (MS) suggest that environmental factors influence the risk of the disease. In particular, the prevalence of MS is higher in those industrialized nations where infectious diseases are fewer and tend to occur later in life than in the developing nations. The serological evidence for past infections in MS patients as possible co-factors for MS has been investigated in many studies since the 1960s [1-7]. We investigated in children with MS and in sexand age-matched controls concentrations of specific antibody against 10 common infectious agents, which had been described to be significantly elevated in MS patients by previous studies [3-7]. There have been no reported associations with MS of any fresh or recent or reactivated infection (IgM antibody). Based on our own observations a possible exception might be Chlamydia pneumoniae (CP) and was therefore included in this study. Children with MS offer a unique opportunity to study a possible infectious background as most of the infections of putative relevance are experienced during childhood.

\section{Methods}

Groups of patients and controls, as described in a previous study [2], were increased in number to 152 in each group (Table 1). The mean age at the time

\footnotetext{
${ }^{1}$ Department of Virology, Georg August University Goettingen,Germany

2 Department of Paediatrics and Paediatric Neurology, Georg August University Goettingen, Germany

${ }^{3}$ Department of Paediatrics and Paediatric Neurology, Medical University Innsbruck, Austria

${ }^{4}$ Department of Medical Statistics, Georg August University Goettingen, Germany

${ }^{5}$ Centre of Human Genetics, University of Marburg, Germany

${ }^{6}$ Centre for Infectious Diseases and International Health, University College London, UK

*Member of these departments until August 2004 (DP), December 2004 (FO), October 2006 (EK), February 2007 (KR). Author for correspondence: Bernd Krone, Department of Virology, Georg August University Goettingen, Kreuzbergring 57, 37075 Goettingen, Germany. E-mail: bkrone@gwdg.de Received 12 October 2006; revised 22 March 2007; accepted 4 June 2007
} 
of serum sample acquisition was 13.40 years for the MS patients and 13.45 years for the matched control subjects. Controls were recruited between 1989 and 2006 and none had suspected acute infections with the analysed agents.

\section{Antibody detection and quantitation}

Sera were obtained from the patients during their first stay in the hospital and were stored frozen below $-20{ }^{\circ} \mathrm{C}$ for subsequent analysis in parallel with the controls. All tests were validated for the intended use by the manufacturers as notified by the European Community (CE) sign. ELISA kits from Virion Serion ${ }^{\circledR}$, Wuerzburg, Germany, were used to test for IgG antibody against adenovirus, herpes simplex $1 / 2$, herpes simplex 2, influenza $A$, measles, mumps, parainfluenza type 2 and varicella; ELISA kits from Euroimmun, Luebeck, Germany, for IgG antibody against herpes simplex $1 \mathrm{gC} 1$ and herpes simplex 2 gG2 recombinant proteins and an ELISA kits from Savyon Diagnostics distributed by Hain Lifescience, Nehren, Germany, were used to assay IgM and IgG antibody against CP. For the assays, $100 \mu \mathrm{L}$ amounts of serum diluted 1:100 (or 1:500 for influenza A) were applied to antigen-coated wells. Colour was developed by the sequential addition of polyclonal anti-human IgG or IgM raised in

Table 1 Characteristics of paediatric MS patients $(n=152)$

\begin{tabular}{|c|c|c|}
\hline Characteristics & $\begin{array}{l}\text { Number } \\
\text { of patients }\end{array}$ & $\begin{array}{l}\text { Percentage } \\
\text { of patients }\end{array}$ \\
\hline \multicolumn{3}{|l|}{ Gender } \\
\hline Female & 102 & 67.1 \\
\hline Male & 50 & 32.9 \\
\hline \multicolumn{3}{|l|}{ Age at first attack (y) } \\
\hline Mean (Median) & $12.3(13.1)$ & \\
\hline Range & $4.04-15.99$ & \\
\hline \multicolumn{3}{|l|}{$\begin{array}{l}\text { Disease course at time of serum } \\
\text { acquisition }\end{array}$} \\
\hline Relapsing remitting & 149 & 98.0 \\
\hline Primary progressive & 2 & 1.3 \\
\hline Secondary progressive & 1 & 0.7 \\
\hline \multicolumn{3}{|l|}{$\begin{array}{l}\text { Serum acquisition: time from } \\
\text { first attack (years) }\end{array}$} \\
\hline Mean (Median) & $1.10(0.43)$ & \\
\hline Range & $0.01-5.87$ & \\
\hline \multicolumn{3}{|l|}{$\begin{array}{l}\text { CSF findings (available for } 132 \\
\text { patients) }\end{array}$} \\
\hline Intrathecal lgG fraction $>10 \%$ & 95 & 72.0 \\
\hline Oligoclonal IgG & 131 & 99.2 \\
\hline \multicolumn{3}{|l|}{$\begin{array}{l}\text { Immuno-modulatory or - } \\
\text { suppressive therapy at } \\
\text { the time of serum acquisition }\end{array}$} \\
\hline Corticosteroids & 16 & 10.5 \\
\hline Beta-interferons & 4 & 2.6 \\
\hline Azathioprine & 2 & 1.3 \\
\hline
\end{tabular}

goats and para-nitrophenylphosphate according to the manufacturer's instructions. Software supplied by the manufacturer of the tests was used to calculate concentrations in Units/mL from the Optical density (OD) readings. IgG antibody to HHV-6 was determined quantitatively by ELISA, Panbio, Guilford Rd., Col USA, distributed by Viramed, Planegg, Germany. Rubella antibodies were assayed by a haemagglutination inhibition assay (in-house test) using human erythrocytes and preabsorption of the sera with kaolin. The level of the rubella antibody is expressed as a titre. Before testing for $\operatorname{IgM}$ all sera were preabsorbed to remove IgG. There were insufficient amounts of sera from 25 patients to test for adeno, influenza, parainfluenza, 24 for CP, 16 for HHV-6, 13 for mumps, 9 for rubella, 6 for measles and varicella and 3 for HSV-1/2 antibody, respectively.

\section{Statistical analysis}

Patients and controls were matched with respect to gender and age. Paired ranks-tests [8] were used to compare antibody concentrations, titre or standardized extinctions of ELISA values between the two groups. The Bonferroni-Holm procedure was used to adjust for multiple testing. For statistical analysis the SAS version 9.1 (SAS Institute Inc, Cary, NC, USA) was used.

\section{Results}

Concentrations of specific IgG antibody for influenza A, measles, parainfluenza 2 and varicella differed significantly between patients and controls. Patients also had higher levels of IgG antiHSV-2 (lysate antigen) reactive antibody than controls (Table 2). Testing of those sera that were positive for IgG anti-HSV-1/2 ELISA (lysate antigen) for antibody against the individual recombinant viral proteins gC1 of $\mathrm{HSV}-1$ and gG2 of HSV-2 revealed that all these children had experienced HSV-1 infections and that, additionally, five children (three patients and two controls) had antibody responses to the recombinant HSV-2 gG2 protein, though only weak. There was no evidence among either patients or controls for infection with HSV-2 only.

The great majority of the children with MS (95.6\%) were positive for IgG anti-HHV-6 antibody. They did not differ significantly from the controls in respect to antibody prevalence and concentration (Table 2). The prevalence of detectable IgG antibody to CP was almost identical (49.2\% and $48.0 \%$, respectively). The IgM antibody prevalence 
Table 2 IgG antibody prevalences and antibody levels against common infections in comparison of paediatric MS patients with matched control subjects

\begin{tabular}{|c|c|c|c|c|c|c|c|c|c|c|}
\hline \multirow[t]{2}{*}{ Infection } & \multicolumn{2}{|c|}{ Adenovirus* } & \multicolumn{2}{|c|}{ HHV-6 } & \multicolumn{2}{|c|}{ HSV-1/2 } & \multicolumn{2}{|c|}{$\mathrm{HSV}-2^{f}$} & \multicolumn{2}{|c|}{ Influenza $A^{*}$} \\
\hline & Patients & Controls & Patients & Controls & Patients & Controls & Patients & Controls & Patients & Controls \\
\hline Number ${ }^{a}$ & 8 & 20 & 126 & 144 & 68 & 71 & 65 & 68 & 24 & 15 \\
\hline Prevalence (\%) & 6.3 & 13.2 & 95.6 & 94.7 & 51.0 & 46.7 & 43.5 & 36.2 & 18.9 & 9.9 \\
\hline Lowest level $^{\mathrm{b}}$ & 0.062 & 0.058 & 25 & 24 & 32 & 35 & 10 & 8 & 0.077 & 0.065 \\
\hline Highest level ${ }^{b}$ & 0.910 & 1.063 & 1310 & 1120 & 11410 & 4020 & 2883 & 435 & 1.115 & 1.390 \\
\hline Mean $^{c}$ & 0.380 & 0.271 & 213 & 215 & 1410 & 951 & 448 & 119 & 0.294 & 0.298 \\
\hline Ratio of means ${ }^{d}$ & \multicolumn{2}{|c|}{1.402} & \multicolumn{2}{|c|}{0.990} & \multicolumn{2}{|c|}{1.483} & \multicolumn{2}{|c|}{3.765} & \multicolumn{2}{|c|}{0.987} \\
\hline Median $^{c}$ & 0.197 & 0.222 & 128 & 125 & 736 & 741 & 426 & 89 & 0.228 & 0.190 \\
\hline Ratio of medians ${ }^{\mathrm{d}}$ & 0.8 & & & & & 93 & 4.7 & & & 00 \\
\hline$P$-value ${ }^{\mathrm{e}}$ & 0 & & & & & & $<0$ & 001 & & 35 \\
\hline \multirow[t]{2}{*}{ Infection } & \multicolumn{2}{|c|}{ Measles } & \multicolumn{2}{|c|}{ Mumps } & \multicolumn{2}{|c|}{ Parainfluenza2* } & \multicolumn{2}{|c|}{ Rubella } & \multicolumn{2}{|c|}{ Varicella } \\
\hline & Patients & Controls & Patients & Controls & Patients & Controls & Patients & Controls & Patients & Controls \\
\hline Number ${ }^{a}$ & 70 & 137 & 74 & 122 & 27 & 30 & 101 & 123 & 88 & 147 \\
\hline Prevalence (\%) & 85.6 & 90.1 & 82.0 & 73.0 & 22.0 & 19.7 & 82.5 & 80.9 & 88.4 & 96.7 \\
\hline Lowest level ${ }^{\mathrm{b}}$ & 181 & 180 & 74 & 77 & 0.074 & 0.105 & 8 & 8 & 103 & 106 \\
\hline Highest level $^{\mathrm{b}}$ & 9390 & 9910 & 5390 & 4800 & 1.087 & 0.788 & 512 & 256 & 6730 & 5490 \\
\hline Meanc & 1469 & 1715 & 354 & 368 & 0.386 & 0.364 & 60 & 43 & 1283 & 655 \\
\hline Ratio of means ${ }^{d}$ & \multicolumn{2}{|c|}{0.857} & \multicolumn{2}{|c|}{0.962} & \multicolumn{2}{|c|}{1.011} & \multicolumn{2}{|c|}{1.395} & \multicolumn{2}{|c|}{1.959} \\
\hline Median ${ }^{c}$ & 1165 & 1137 & 191 & 233 & 0.357 & 0.343 & 32 & 32 & 896 & 575 \\
\hline Ratio of medians ${ }^{d}$ & \multicolumn{2}{|c|}{1.025} & \multicolumn{2}{|c|}{0.820} & \multicolumn{2}{|c|}{1.041} & \multicolumn{2}{|c|}{1.000} & \multicolumn{2}{|c|}{1.558} \\
\hline$P$-value ${ }^{\mathrm{e}}$ & \multicolumn{2}{|c|}{$<0.0001$} & \multicolumn{2}{|c|}{0.29} & \multicolumn{2}{|c|}{0.029} & \multicolumn{2}{|c|}{0.054} & \multicolumn{2}{|c|}{$<0.0001$} \\
\hline
\end{tabular}

${ }^{a}$ numbers of antibody positive patients and antibody positive controls.

bantibody levels.

cantibody concentrations of antibody positive, or of *standardized

$\Delta$ OD-values of all subjects.

${ }^{d}$ ratio of antibody levels of patients relative to controls.

elevation of antibody levels in patients in relation to matched controls as analyzed in paired

ranks-test, with application of the Bonferroni-Holm correction.

flysate antigen. Prevalences of IgG anti-HSV-2 gG2 antibody were 2.0 and $1.3 \%$, respectively.

differed significantly between patients (28.9\%) and controls $(2.0 \%)$.

\section{Discussion}

The substantial evidence for an association of a previous EBV infection to MS was highlighted recently [9-11]. Two previous studies on paediatric MS patients have shown $[1,2]$ that significantly more patients than controls had experienced remote EBV infection and, in the larger, more recently published study [2] it was concluded that possibly all paediatric MS patients had experienced remote EBV infection. Only two of the 147 MS patients were EBV antibody negative and these may represent the 'false negatives', which would be expected from the distribution of the antibody concentrations in a population of this size previously infected with EBV.Complex differences in antibody responses to some infections other than EBV have been reported between adult patients with MS and control subjects [3-7] and, in the present study, such differ- ences have also been shown to occur in children. With the exceptions of EBV $[1,2,9]$ and CP, the association with MS is only indicated by the slight though significantly elevated antibody concentration in the patients to certain infections: influenza A, measles, parainfluenza 2 and varicella. In contrast, we did not demonstrate significantly elevated titre or concentrations of IgG antibody to rubella, HHV-6 and adenoviruses in the patient group, possibly because of sample size limitation. Moreover, there are more than 60 types of adenoviruses, and association with MS may be restricted to just some types, which are not differentiated by the diagnostic antigen used.

Of all prior observations, those on herpes simplex serology in MS patients are the least clear $[5,12,13]$. The present study showed no association of HSV-1 with MS, whereas an MS-association seemed to be confirmed by the HSV-2 antibody test $[3,12]$. However, the HSV-2 lysate antigen ELISA is strongly cross-reacting with antibodies directed against the heterotypic virus in the patient as well as in the control group. The analysis of antibodies to the 
recombinant gG2 proteins of HSV-2 revealed only for three patients and two control subjects evidence suggestive of a possible prior infection with HSV-2.

There have been many investigations on $\mathrm{CP}$ DNA in MS and a meta-analysis of inconsistent studies has recently been published [14]. An association of CP infection and MS is indicated in our study by a significantly higher prevalence of specific IgM antibody in the patients, an association that has not yet been reported in adult MS patients [15]. The high prevalence might be caused by a higher frequency for reactivation of this infection in the patients.

The data on different antibody levels indicative of infection by a range of pathogens in MS cannot be interpreted in a simple way that enables a deleterious or beneficial role to be attributed to a single agent. The finding that antibodies to only certain infectious agents are elevated suggests that different forms of repeated contact with the same or related antigen are a more likely explanation than polyclonal B-cell stimulation. Another possibility is a different timing of infections or vaccinations in MS patients and controls. Within the time period of this study children in Germany were mostly vaccinated against mumps, measles and rubella, while 10, 12 and 20\%, respectively, still had histories of the natural infectious diseases [16]. In general, this study supports a complex infectious and/or immunological background of MS rather than the causative role of a single pathogen and, certainly, no single infectious agent has so far been shown to explain all aspects of the epidemiology of MS [6].

\section{Acknowledgements}

We thank the children, adolescents and their parents who kindly took part in this study, Mrs. Ulrike Boelling and Mrs. Karin Thiele for valuable technical support and the Hertie-Stiftung (GHS 1910017), Virion-Serion, Wuerzburg, Euroimmun, Luebeck, Viramed Biotech, Planegg/Steinkirchen and Hain Lifescience, Nehren, all in Germany, for financial support. The study was approved by the ethics committee of the Medical Faculty, University of Goettingen.

\section{References}

1. Alotaibi S, Kennedy J, Tellier R, Stephens D, Banwell B. Epstein-Barr virus in pediatric multiple sclerosis. J Amer Med Assoc 2004; 291: 1875-79.

2. Pohl D, Krone B, Rostasy K, Kahler E, Brunner E, Lehnert $\mathbf{M}$, et al. High seroprevalence of Epstein-Barr virus in children with multiple sclerosis. Neurology 2006; 67: 2063-65.

3. Norby E. Viral antibodies in multiple sclerosis. Prog Med Virol 1978; 24: 1-39.

4. Cook SD, Rohowsky-Kochan C, Bansil S, Dowling PC. Evidence for multiple sclerosis as an infectious disease. Acta Neurol Scand 1995; (Suppl) 161: 34-42.

5. Simmons A. Herpesviruses and multiple sclerosis. Herpes $2001 ; \mathbf{8}$ : 60-3.

6. Haahr S, Höllsberg P. The ability of candidate viruses to explain epidemiological findings in multiple sclerosis. In: Hommes OR, Clanet $\mathrm{M}$, Wekerle $\mathrm{H}$ eds. Genes and viruses in multiple sclerosis. Amsterdam: Elsevier; 2001: 163-84.

7. Swanborg RH, Whittum-Hudson JA, Hudson AP. Infectious agents and multiple sclerosis - are Chlamydia pneumoniae and human herpes virus 6 involved? $J$ Neuroimmunol 2003; 136: 1-8.

8. Munzel U. Nonparametric methods for paired samples. Statistica Neerlandica 1999; 53: 277-86.

9. Haahr S, Höllsberg P. Multiple sclerosis is linked to Epstein-Barr virus infection. Rev Med Virol 2006; 16: 297-310.

10. Levin LI, Munger KL, Rubertone MV, Peck CA, Lennette ET, Spiegelman D, et al. Temporal relationship between elevation of Epstein-Barr virus antibody titers and initial onset of neurological symptoms in multiple sclerosis. I Amer Med Assoc 2005; 293: 2469-500.

11. DeLorenze GN, Munger KL, Lenette ET, Orentreich N, Vogelman JH, Ascherio A. EpsteinBarr virus and multiple sclerosis - Evidence of association from a prospective study with long-term follow-up. Arch Neurol 2006; 63: 839-44.

12. Catalano LW Jr. Herpesvirus hominis antibody in multiple sclerosis and amyotropic lateral sclerosis. Neurology 1972; 22: 473-8

13. MacGregor HS, Latiwonk QI. Complex role of gamma-herpesviruses in multiple sclerosis and infectious mononucleosis. Neurol Res 1993; 15: 391-4.

14. Bagos PG, Nikolopoulos G, Ioannidis A. Chlamydia pneumoniae infection and the risk of multiple sclerosis: a meta-analysis. Mult Scler 2006; 12: 397-411.

15. Munger KL, DeLorenze GN, Levin LI, Rubertone MV, Vogelman JH, Peck CA, et al. A prospective study of Chlamydia pneumoniae infection and risk of MS in two US cohorts. Neurology 2004; 25: 1799-803.

16. Reinhardt D, Houliara K, Pekrun A, Lakomek M, Krone B. Impact of conventional chemotherapy on levels of antibodies against vaccine-preventable diseases in children treated for cancer. Scand J Infect Dis 2003; 35: 851-57. 